\title{
Flowering regulation in the facultative biennial Oenothera biennis L.: Environmental effects and their relation to growth rate
}

\author{
Raúl Giménez ${ }^{a}$, Daniel M. Sorlino ${ }^{a}$, Héctor D. Bertero ${ }^{\mathrm{b}, \mathrm{c}}$, Edmundo L. Ploschuk $^{\mathrm{a}, *}$ \\ a Cátedra de Cultivos Industriales, FAUBA, Av. San Martín 4453, C1417DSE Buenos Aires, Argentina \\ b Cátedra de Producción Vegetal FAUBA, Av. San Martín 4453, C1417DSE Buenos Aires, Argentina \\ c CONICET, Argentina
}

\section{A R T I C L E I N F O}

\section{Article history:}

Received 3 July 2012

Received in revised form

12 September 2012

Accepted 23 September 2012

\section{Keywords:}

Oenothera biennis

Flowering

Photoperiod

Vernalization

Growth rate

High temperature

\begin{abstract}
A B S T R A C T
The lifecycle of the facultative biennial oilseed-crop evening primrose (Oenothera biennis) is a major constraint for its commercial production under different growing conditions, as a variable proportion of plants fails to flower during the first season and remains as vegetative rosettes (biennial behavior). The aim of this work was to understand how flowering is regulated in this species and to identify the main determinants of its biennial behavior.

Different planting dates and manipulative treatments (seed vernalization, photoperiod extension and fertilization) were employed to analyze if: (i) biennial behavior occurs when obligate requirements for vernalization or photoperiod are not satisfied; and (ii) responses to these environmental cues depend on the size and/or growth rate of rosettes.

Our results indicate that $O$. biennis has an obligate long-day requirement for flowering and a facultative vernalization response. There is no minimum size requirement for vernalization response (as very small seedlings responded to the vernalization treatment) and the rate of development toward flowering under inductive photoperiods was strongly affected by rosette's growth rate. The incidence of high temperatures just before the onset of reproduction is proposed as an inhibitory factor that prevents reproduction under otherwise photo-inductive conditions. This last factor would explain the high incidence of biennial behavior frequently observed in spring/summer sowing in this crop.
\end{abstract}

(ㅇ) 2012 Elsevier B.V. All rights reserved.

\section{Introduction}

Evening primrose (Oenothera biennis L., Onagraceae) is a facultative biennial plant species native to eastern and central North America and recently domesticated as a specialty oilseed-crop (Lapinskas, 1999; Fieldsend, 2007). Its value lies in its seed oil which contains unusually high levels of gamma-linolenic acid (GLA), an uncommon fatty acid used in pharmaceuticals and nutritional supplements (Hudson, 1984; Russell, 1988; Horrobin, 1992). Although other plant species such as borage (Borago officinalis L.) or blackcurrant (Ribes nigrum L.) offer higher GLA concentrations, evening primrose remains the most suitable source of GLA because of its very simple oil profile and its potential for agricultural production (Lapinskas, 1993, 1999; Liu et al., 2003; Ghasemnezhad, 2007).

As a novel crop, evening primrose faces a number of problems for its production on a commercial scale. Among the most

\footnotetext{
* Corresponding author. Tel.: +54 114524 8040/8075.

E-mail addresses: gimenezr@agro.uba.ar (R. Giménez), dsorlino@agro.uba.ar (D.M. Sorlino), bertero@agro.uba.ar (H.D. Bertero), ploschuk@agro.uba.ar (E.L. Ploschuk).
}

important is the extended lifecycle due to its biennial reproductive behavior (Lapinskas, 1982, 1993; Liu et al., 2003; Ghasemnezhad, 2007). In its biennial form, O. biennis is sown in summer or autumn, overwinters as a vegetative rosette, and develops a reproductive stalk in spring (bolting). It flowers and ripens during the following summer and is harvested in autumn, occupying the field during 14 months (Horrobin and Lapinskas, 1993; Lapinskas, 1993). Many hybrids and varieties have been released by breeding programs with shorter life cycles (Lapinskas, 1999; Fieldsend and Morison, 2000; Liu et al., 2003; Kapoor and Nair, 2005; Fieldsend, 2007) that made it possible to sow in spring (spring evening primrose) as an alternative to summer-autumn sowings (winter evening primrose) (Horrobin and Lapinskas, 1993; Ghasemnezhad, 2007). Spring-sown crops have a shorter vegetative phase and total life cycle, without major impact on grain yield or oil quality (Ghasemnezhad and Honermeier, 2008). As a consequence they fit better into crop rotation schemes and present lower weed and diseases control costs (Reeleder, 1994; Fieldsend and Morison, 2000). Despite these advantages summer sowings, or combinations of summer and spring sowings, are still preferred in many production areas (Horrobin and Lapinskas, 1993; Fieldsend and Morison, 2000; Fieldsend, 2004; Król, 2007) because they present a lower uncertainty in yield expectations. 
Bolting failure has been reported as an important productive constraint in spring evening primrose that can determine the success or failure of the crop (Lotti et al., 1984; Lapinskas, 1999; Deng et al., 2001; Król, 2007) and mainly explains the lower yield stability of this management option. A variable proportion of plants in a crop may not initiate reproduction in spring, remaining as vegetative rosettes until harvest time in autumn. As these plants would neither bolt nor flower until the following spring (i.e. they behave as biennials), they do not contribute to seed yield (Król, 2007). Knowledge of factors involved in the transition from vegetative growth to reproductive development in 0 . biennis is important not only to explain its annual or biennial behavior in different environments, but also to determine the feasibility of the crop in areas where it has not been grown before.

Although several flowering control factors have been proposed, an integrated analysis of how reproductive behavior of $O$. biennis is controlled is still lacking. Biennial behavior could be explained as the consequence of the dissatisfaction of an obligate requirement for one or more developmental factors, like vernalization or long photoperiods (Chouard, 1960; Picard, 1967; Reekie and Reekie, 1991; Lapinskas, 1993; Liu et al., 2003). Besides this, there is evidence that factors usually associated with growth could also be involved (Kromer and Gross, 1987; Roy et al., 1993; Lapinskas, 1999; Król and Berbeć, 2004; Król, 2007). Several authors agree that facultative biennial plant species must reach a minimum critical size to trigger flower initiation in response to environmental stimuli (Werner, 1975; Gross, 1981; Kachi and Hirose, 1983; Klinkhamer et al., 1987). In this way, environments that restrict growth would promote biennial behavior by not allowing the plant to attain the critical size before inductive conditions occur (Kachi and Hirose, 1985; Kagaya et al., 2009).

The aim of this work was to identify the main determinants of biennial behavior in $O$. biennis by analyzing the effect of vernalization, photoperiod and their interactions with plant growth under different growing conditions. Two hypotheses were tested: (H1) biennial behavior occurs when obligate requirements for vernalization or photoperiod are not satisfied; and $(\mathbf{H 2})$ response to these environmental cues depends on the size and/or growth rate of rosettes.

\section{Material and methods}

\subsection{General}

Field experiments were performed at the Faculty of Agronomy of the University of Buenos Aires, Argentina (34 $35^{\prime} \mathrm{S}, 58^{\circ} 29^{\prime} \mathrm{W}$ ) between years 2005 and 2010. These experiments were conducted in pots under semi-controlled field conditions in which different planting dates (PD) were employed to explore a broad range of photo-thermal environments (Table 1 ). In every PD (save for those including a vernalization treatment described in the next section) seedlings were grown in germination trays ( $40 \mathrm{ml}$ plastic boxes) containing a peat-based substratum (Dynamics $1^{\circledR}$ ), in a greenhouse. When seedlings were considered to be large enough to withstand field conditions (between 3 and 5 leaves), they were transplanted outdoors to 71 pots (one plant per pot) containing a mixture of local soil and sand (5:4). In the field, pots were arranged in plots with 3 replicates (plots) per treatment. The number of pots per replicate was variable (see Table 1 ) with a distance between plants of $0.3 \mathrm{~m}$. Plants were hand-weeded and watered as needed. Cipermetrine $25 \%\left(20 \mathrm{~cm}^{3} \mathrm{hl}^{-1}\right)$ and Zineb $70 \%$ $\left(20 \mathrm{~g} \mathrm{hl}^{-1}\right)$ were applied every 15 days to prevent pest and fungal diseases. Maximum and minimum daily temperatures were obtained from an automatic meteorological station located $200 \mathrm{~m}$ from the experimental site, and daylength was calculated from U.S.
Naval Observatory data (www.usno.navy.mil), considering natural daylength plus civil twilights. $O$. biennis seeds were provided by Marisol Berti Diaz (University of Concepcion, Chile) and derive from a population provided by Kings (currently Technology Crops Ltd., UK) after several cycles of multiplication in central Chile.

\subsection{Vernalization experiments}

Planting dates $\mathbf{a}, \mathbf{b}$ and $\mathbf{f}$ (Table 1 ), included a seed-vernalization treatment to determine if a period of low temperature is an obligate requirement for 0 . flowering, and to evaluate if the species can be vernalized at this stage. Seed vernalization treatments $(\mathbf{V n +}$ consisted in keeping pre-germinated seeds in a $5^{\circ} \mathrm{C}$ growth chamber for 5 weeks. Vn+ seeds were pre-germinated in a $20 / 30^{\circ} \mathrm{C}$ growth chamber and once germinated, buried in plastic trays $(17 \times 12 \times 5 \mathrm{~cm})$ with sterilized moistened sand and placed in the $5{ }^{\circ} \mathrm{C}$ growth chamber. Non-vernalized treatments $(\mathbf{V n}-)$ started a week before the end of the $\mathbf{V n}+$ treatment. $\mathbf{V n}$ - seeds where pregerminated and buried in similar plastic trays but maintained in a $20 / 30^{\circ} \mathrm{C}$ growth chamber until plants reached the same stage of development as $\mathbf{V n +}$ (hypocotyl length of $0.5-1.5 \mathrm{~cm}$ ). Seedlings from both treatments were then transplanted to germination trays, and maintained under greenhouse conditions ( 8 weeks) until transplant to pots in the field under natural photoperiods. In planting date a (late winter), a greenhouse conditioned to keep temperature above $10^{\circ} \mathrm{C}$, was used to minimize the risk of natural vernalization. A completely randomized design was used in these experiments.

\subsection{Photoperiod and fertilization experiments}

Artificial daylength extensions were used in some PDs (Table 1) to analyze the effect of photoperiod under contrasting growing conditions. Natural photoperiod $\left(\mathbf{P P}_{\mathbf{N}}\right)$ was extended to a constant $18 \mathrm{~h}$-daylength $\left(\mathbf{P P}_{\mathbf{1 8}}\right)$ by using a combination of lamps (two $45 \mathrm{~W}$ incandescent bulbs and one $30 \mathrm{~W}$ fluorescent tube per plot, adding $\approx 0.43 \mathrm{MJ}$ per hour of photoperiod extension) programmed to automatically turn on and off by an electronic timer (from $0500 \mathrm{~h}$ to dawn, and from dusk to $2200 \mathrm{~h}$ ). In planting date c, an additional photoperiod level (15 h per day, $\mathbf{P P}_{\mathbf{1 5}}$ ) and a fertilization treatment $(\mathbf{N})$ were included to increase variability in plant growth and to explore photoperiod by fertilization interactions. A complete randomized design was used for the photoperiod experiments, and a factorial split-plot design was employed for the photoperiod $\times$ fertilization one, using photoperiod as the main plot (3 levels: $\mathbf{P P}_{\mathbf{1 8}}, \mathbf{P P}_{\mathbf{1 5}}$ and $\mathbf{P P}_{\mathbf{N}}$ ) and fertilization as subplots (2 levels: $\mathbf{N}+$, fertilized and $\mathbf{N}$-, without fertilization). $\mathbf{N}+$ consisted of the application of $2 \mathrm{~g}$ per pot of a granular NPK fertilizer (20-20-20), $10 \mathrm{~d}$ prior to transplant. $\mathbf{N}$ was also applied in summer planting date e, but no daylength extension was used in that experiment.

\subsection{Phenology and growth determinations}

Flower beginning time (FBT) was defined as the time from transplant to the beginning of flowering and was registered in every individual plant for each PD. The proportion of plants that flowered (at least one open flower in the main stem) before the second growing season (i.e. the second spring-summer period in a plant lifecycle) was used to estimate the \% of annual plants (\%An); otherwise plants were considered as biennials. The onset of stem elongation (OSE), which precedes flowering was recognized as the first macroscopic sign of the reproductive status and included in the analysis for planting dates $\mathbf{c}$ to $\mathbf{m}$. A plant was registered at $\mathbf{O S E}$ when its stem reached $1 \mathrm{~cm}$ in length, determined by fitting nonlinear functions of plant height against time, with height measured on a 3-4 day-interval. Estimations of rosette area $\left(\mathbf{R A}, \mathrm{cm}^{2}\right)$ were performed twice a week from digital photographs taken from above 
Table 1

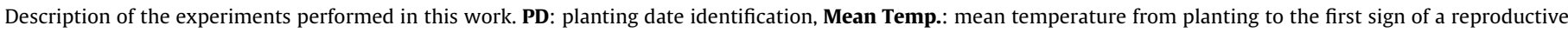

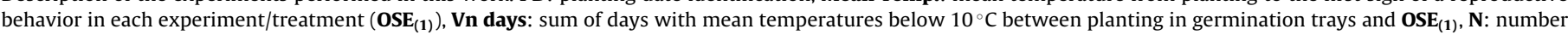

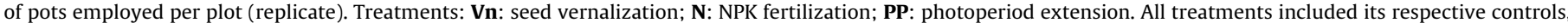

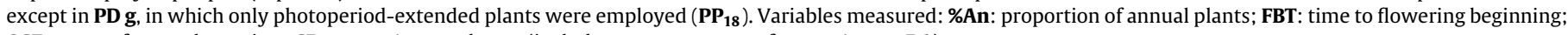
OSE: onset of stem elongation; GR: rosette's growth rate (includes measurements of rosette's area RA).

\begin{tabular}{|c|c|c|c|c|c|c|c|}
\hline PD & Outdoors planting date & Treatments & Onset of treatment & Variables measured & Mean Temp. & Vn days & $\mathbf{N}$ \\
\hline $\mathbf{a}$ & 07 September 2005 & Vn & 16 June & $\% A n ;$ FBT & 16.4 & 5 & 16 \\
\hline b & 09 December 2005 & Vn & 06 September & \%An; FBT & 23.3 & 0 & 16 \\
\hline c & 13 October 2006 & $\mathbf{N} ; \mathbf{P P}$ & 13 October; 17 October & \%An; FBT; OSE & 19.3 & 14 & 10 \\
\hline d & 21 May. 2007 & PP & 19 June & \%An; FBT; OSE; GR & 10.1 & 29 & 18 \\
\hline $\mathbf{e}$ & 10 January 2008 & $\mathbf{N}$ & 01 January & \%An; FBT & 25.0 & 0 & 12 \\
\hline f & 29 January 2008 & Vn; PP & 26 November; 1 February & \%An; FBT; OSE; GR & 24.8 & 0 & 8 \\
\hline g & 11 July 2008 & PP & 16 July & \%An; FBT; OSE; GR & 14.1 & 14 & 20 \\
\hline h & 06 August 2008 & PP & 11 August & \%An; FBT; OSE; GR & 13.9 & 10 & 32 \\
\hline $\mathbf{i}$ & 11 November 2008 & PP & 11 November & \%An; FBT; OSE; GR & 23.5 & 0 & 20 \\
\hline $\mathbf{j}$ & 20 November 2008 & PP & 21 November & \%An; FBT; OSE & 24.2 & 0 & 16 \\
\hline $\mathbf{k}$ & 05 February 2009 & PP & 14 February & \%An; FBT; OSE; GR & 24.6 & 0 & 20 \\
\hline 1 & 18 March 2010 & PP & 24 March & \%An; FBT; OSE; GR & 21.3 & 0 & 21 \\
\hline m & 08 July 2010 & PP & 09 July & \%An; FBT; OSE & 9.5 & 25 & 7 \\
\hline
\end{tabular}

the plants, and analyzed with an image-processing software (UTHSCSA Image Tool 3.00). Growth rate $\left(\mathbf{G R}, \mathrm{cm}^{2} \mathrm{~d}^{-1}\right)$ was calculated for each plant as the ratio of the difference between two consecutive RA measurements and the time interval between them.

\subsection{Data analysis}

Two-tailed unpaired t-tests were performed to evaluate differences $(p<0.05)$ in \%An and FBT between $\mathbf{V n}+$ and $\mathbf{V n}-$ (planting dates $\mathbf{a}, \mathbf{b}$ and $\mathbf{f}$ ) or $\mathbf{P P}_{\mathbf{1 8}}$ and $\mathbf{P P}_{\mathbf{N}}$ (planting dates $\mathbf{c}$ to $\mathbf{m}$ ). \%An data were analyzed following arcsine transformation (Little and Hills, 1975). In PD c, a two-way ANOVA was employed to quantify the effects of photoperiod, fertilization and their interaction on \%An and duration of two developmental phases of annual plants: planting to OSE and OSE to flowering. Additionally, linear and nonlinear regression analyses were employed on annual plants data from $\mathbf{P P}_{18}$ treatments in different $\mathbf{P D}$ to determine if the rate of development toward OSE ( $\mathbf{D R}_{\mathbf{P P}-\mathbf{O S E}}$ ) under photo-inductive conditions is modulated by the size ( $\mathbf{R} \mathbf{A}_{\mathbf{P P}}$, rosette area at the onset of the photoperiod treatment) or growth rate $\left(\mathbf{G R}_{\mathbf{P P}}\right.$, mean growth rate of rosettes during the photoperiod treatment) of rosettes. $\mathbf{G R}_{\mathbf{P P}}$ was calculated for every plant as the mean GR between the onset of the photoperiod treatment and that of reproduction $\left(\mathbf{O S E}_{(\mathbf{1})}\right.$, the date when the first $\mathbf{P P}_{\mathbf{1 8}}$ plant in the experiment reached the $\mathbf{O S E}$ status). The period before $\mathbf{O S E}_{(\mathbf{1})}$ was chosen to exclude reproductive effects on GR of the most developmentally advanced plants within a treatment.

\section{Results}

\subsection{Planting date effects}

The different environments provided by planting dates highly impacted on the type of reproductive behavior (annual or biennial) of $O$. biennis, and the length of the pre-flowering phase of annual plants (Fig. 1). No biennial plants were registered in May to August PDs (late autumn to mid-winter). Biennial behavior was increasingly evident in late-winter to summer PDs as an abrupt decrease in \%An. In summer PDs almost none of the plants flowered during the first growing season. The length of the pre-flowering phase (FBT) of annual plants shortened as PD was delayed from May (178 d) to December ( $55 \mathrm{~d}$ ). Differences in lifecycle length between plants of different reproductive behavior can be inferred from the January planting date (PD f), when biennial plants flowered more than 200 days later than annual plants.

\subsection{Vernalization effect}

Seed-vernalization treatment ( $\mathbf{V n +}$ ) increased \%An, and accelerated the rate of development toward flowering in both planting dates $\mathbf{a}$ and $\mathbf{b}$ (late winter and spring, respectively), but not in planting date $\mathbf{f}$ (mid summer), where none of the plants exposed to natural daylength flowered in the first growing season, regardless of their vernalization treatment (Fig. 2). In PD a vernalized plants $(\mathbf{V n +})$ flowered 4.5 days before non-vernalized plants $(\mathbf{V n}-$, $p<0.05$ ) and the proportion of annual plants increased from $82 \%$ in $\mathbf{V n}-$ to $94 \%$ in $\mathbf{V n +}(p<0.05)$. A similar pattern was observed in PD b in which vernalization tended to increase \%An (from 34\% to $52 \%$ for $\mathbf{V n}-$ and $\mathbf{V n +}$, respectively, $p<0.1$ ) and to shorten FBT in 2.6 days ( $p=0.13)$. Compared to PD a, PD b presented a lower \%An and a shorter FBT, in accordance with the general response to planting date variation observed in Fig. 1.

\subsection{Photoperiod effect}

Daylength extension had a major impact in determining the reproductive behavior of $O$. biennis. In summer PDs in which annual behavior did not naturally occur (Fig. 1) $\mathbf{P P}_{\mathbf{1 8}}$ treatment increased \%An to $83.3 \%, 96.7 \%$ and $98.4 \%$ for PD f, $\mathbf{k}$ and $\mathbf{1}$, respectively but

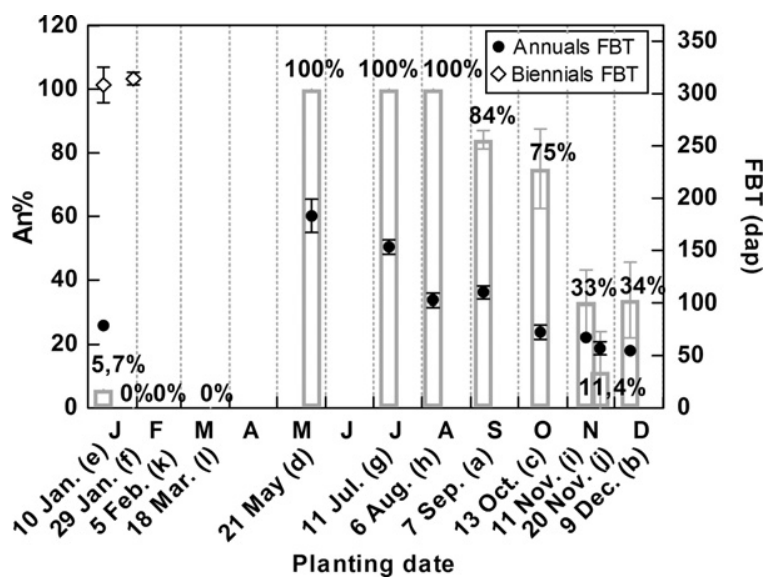

Fig. 1. Proportion of annual plants (\%An; bars) and flowering beginning time (FBT; days after outdoor planting; points) of plants of Oenothera biennis from different planting dates. Closed symbols represent mean FBT of annual plants and open symbols represent FBT of plants with biennial behavior (only for two planting dates). Letters between brackets indicate planting date identification as presented in Table 1. Vertical segments in each bar/symbol represent the standard error of the means. 


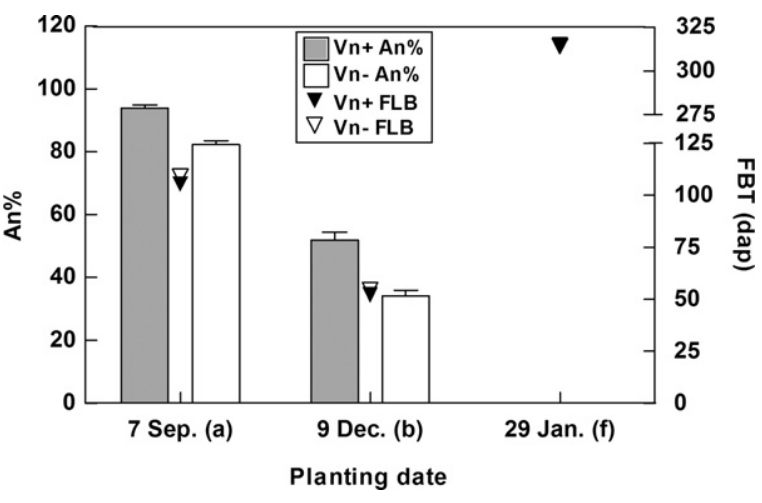

Fig. 2. Proportion of annual plants (\%An; bars) and flowering beginning time (FBT; days after outdoor planting; triangles) of seed-vernalized (filled bars; closed triangles) and non-vernalized (open bars; open triangles) Oenothera biennis plants from different outdoors planting dates. Letters between brackets indicate planting date identification as presented in Table 1. Vertical segments in each bar/symbol represent the standard error of the means.

was not sufficient to reduce the high incidence of biennial behavior commonly observed in late-spring PDs (i.e. PDs $\mathbf{i}$ and $\mathbf{j}$ ), suggesting that other factor/s could be involved in flower induction under those conditions (Fig. 3). Like for seed-vernalization responses, $\mathbf{P P}_{18}$ affected not only \%An but also reduced FBT of annual plants. Differences between photoperiod treatments were reduced as PD was delayed toward the summer and the difference between natural and extended photoperiod decreased.

\subsection{Photoperiod $\times$ fertilization interactions}

The photoperiod $\times$ fertilization experiment performed in PD c (early spring) showed that, in addition to vernalization and daylength, mineral nutrition has a role in 0 . biennis development (Fig. 4). \%An increased significantly from $75 \pm 7 \%$ to more than $95 \%$ in response to photoperiod extension $(p<0.05)$, NPK fertilization $(p=0.016$; Fig. 4A) or the combination of both. FBT was also modified by photoperiod and NPK fertilization, but their effect differed (Fig. 4B). On the one hand, photoperiod extension anticipated flowering in a similar way in $\mathbf{P P}_{\mathbf{1 5}}$ and $\mathbf{P P}_{\mathbf{1 8}}$, by shortening the length of two developmental sub-phases: planting to OSE ( 5 days shorter in $\mathbf{P P}_{15}$ and $\mathbf{P P}_{18}$ versus $\mathbf{P P}_{\mathbf{N}}, p<0.0001$ ) and $\mathbf{O S E}$ to flowering (8 days shorter in photoperiod-extended treatments, $p<0.0001)$. However,

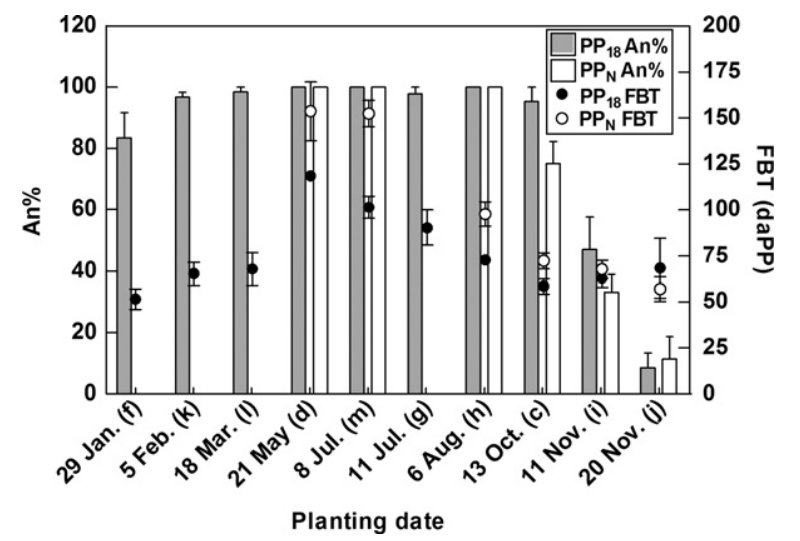

Fig. 3. Proportion of annual plants (An\%, bars) and time to flowering beginning of annual plants (FBT, days after onset of photoperiod treatment; circles) in a 18-h photoperiod-extended treatment ( $\mathbf{P P}_{\mathbf{1 8}}$, filled bars and circles) and a natural daylength treatment ( $\mathbf{P P}_{\mathbf{N}}$, open bars and circles) in different planting dates (identification letter between brackets). In planting date $\mathbf{g}$, only photoperiod-extended $\left(\mathbf{P P}_{18}\right)$ plants were employed, without a control level $\left(\mathbf{P P}_{\mathbf{N}}\right)$. Vertical segments in each bar/symbol represent the standard error of the means. mineral fertilization only shortened the length of the former subphase ( 5 days shorter than non-fertilized treatments, $p<0.0001$ ) but not that of the latter $(p>0.05)$. In PD e, $\mathbf{N}$ treatment did not have a significant effect neither on \%An nor on FBT as arising from the fact that only 2 plants in the experiment (from $\mathbf{N}$ - treatment) presented annual behavior (data not shown).

\subsection{Growth-development relationship}

$\mathbf{D R}_{\mathbf{P P}-\mathbf{O S E}}$ was positively related to $\mathbf{G R}_{\mathbf{P P}}$ of photoperiodextended plants, but this relationship was stronger when data from experiments exposed to warmer temperatures (i.e. higher than $22-23^{\circ} \mathrm{C}$, according to Table 1 ) were excluded from the analysis (Fig. 5A). Under cool growing conditions (PDs d, $\mathbf{g}, \mathbf{h}$ and $\mathbf{i}$ ), DRPP-OSE responded linearly to increasing $\mathbf{G R}_{\mathbf{P P}}$ up to $5 \mathrm{~cm}^{2} \mathrm{~d}^{-1}$, with a diminishing response at higher $\mathbf{G R}_{\mathbf{P P}}$ values. Plants exploring warmer growing conditions (PDs f, i and $\mathbf{k}$ ) presented lower $\mathbf{D R}_{\mathbf{P P}-\mathbf{O S E}}$ values at a given $\mathbf{G R}_{\mathbf{P P}}$, suggesting supraoptimal temperature conditions for development. No relationship was found between $\mathbf{D R}_{\mathbf{P P}-\mathbf{O S E}}$ and $\mathbf{R} \mathbf{A}_{\mathbf{P P}}$ when all $\mathbf{P P}_{\mathbf{1 8}}$ data were analyzed together $\left(r^{2}=0.05\right.$; data not shown). However, a linear association between $\mathbf{G R}_{\mathbf{P P}}$ and $\mathbf{R} \mathbf{A}_{\mathbf{P P}}$ was found when each $\mathbf{P D}$ was analyzed by separate (Fig. 5B), so RA $\mathbf{A}_{\mathbf{P P}}$ would partially determine $\mathbf{D R} \mathbf{R}_{\mathbf{P P}-\mathbf{O S E}}$, through its effect on the subsequent growth rate of rosettes.

\subsection{High temperature effect}

The prevalence of biennial behavior in late-spring planting dates, even when $\mathbf{V n +}(\mathbf{P D} \mathbf{b})$ or $\mathbf{P P}_{\mathbf{1 8}}$ (PDs $\mathbf{i}$ and $\mathbf{j}$ ) treatments were applied, led us to consider the ad-hoc hypothesis that other factors could be preventing the transition to the reproductive phase (OSE) in those conditions. As every plant that reached the OSE status flowered in a short time during the same season, we explored whether environmental conditions prior to OSE have a bearing on the reproductive behavior of $O$. biennis. Accordingly, \%An seems to strongly depend on the time of the year in which OSE started $\left.\mathbf{O S E}_{(\mathbf{1})}\right)$; when OSE occurred in a time window between November and February, there was a proportion of plants that behaved as biennials, even under extended photoperiods (Fig. 6A). This time window coincides with the warmest season of the year, suggesting that high temperatures may have an inhibitory effect on flowering initiation of $O$. biennis. Thus, \%An remained practically at $100 \%$ in those experiments where the onset of reproduction (i.e. an arbitrary chosen period of 15 days starting at $\mathbf{O S E}_{(\mathbf{1})}$ ) coincided with a mean maximum temperature (Tmax) lower than $27^{\circ} \mathrm{C}$, but declined abruptly when this temperature threshold was surpassed (Fig. 6B).

\section{Discussion}

As reported in previous studies, planting date had a major impact on the reproductive behavior of 0 . biennis (Roy et al., 1993; Król, 2007). Under non-manipulated field conditions, annual behavior prevailed in early planting dates (autumn to late winter) and the proportion of biennial plants increased as planting date was delayed from late-winter to summer (Fig. 1).

Although biennial behavior in late sown 0 . biennis (i.e. spring-summer) had previously been attributed to a non-satisfied absolute cold requirement (Chouard, 1960; Picard, 1967; Grignac, 1988; Reekie, 1997; Berti et al., 2006), the evidence from this study does not support this premise. A high proportion of annual plants occurred in Vn- of PD a and a considerable amount of Vnplants also behaved as annuals in PD b, both exploring temperatures usually assumed as non-vernalizing $\left(>10^{\circ} \mathrm{C}\right)$ (Fig. 2$)$, although some degree of natural vernalization cannot be discarded in PD a (Table 1). The absence of an absolute vernalization requirement is also shown in summer PDs $\mathbf{f}$ and $\mathbf{i}$, where photoperiod extensions 

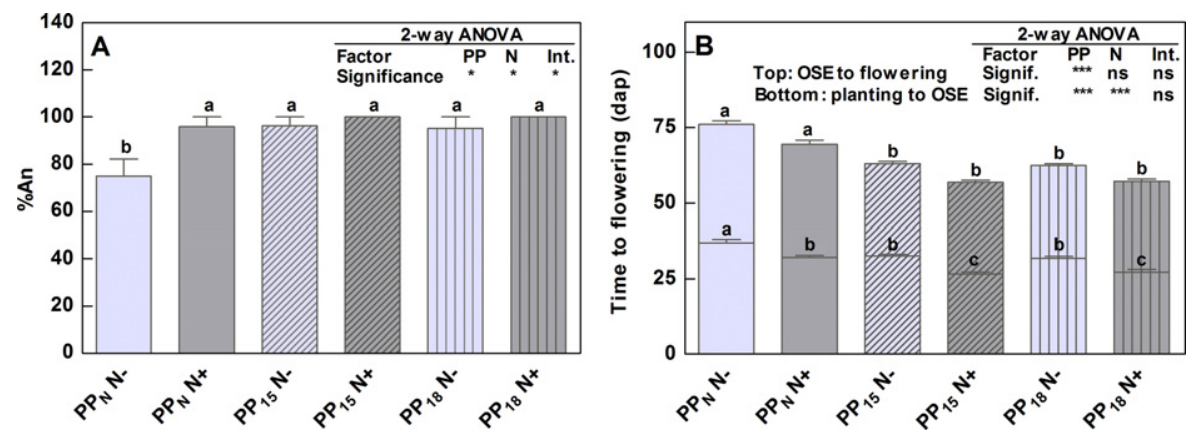

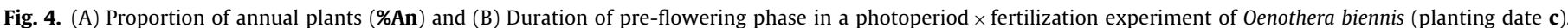

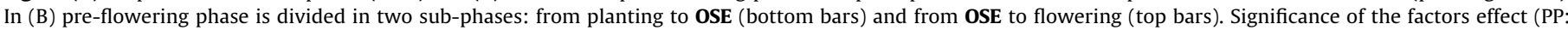

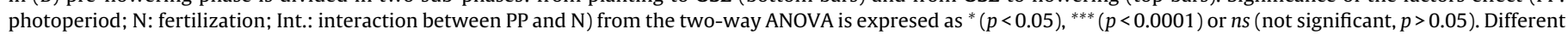
letters indicate significant differences (Tukey, $p<0.05$ ) among treatments. Vertical segments in each bar represent the standard error of the means.
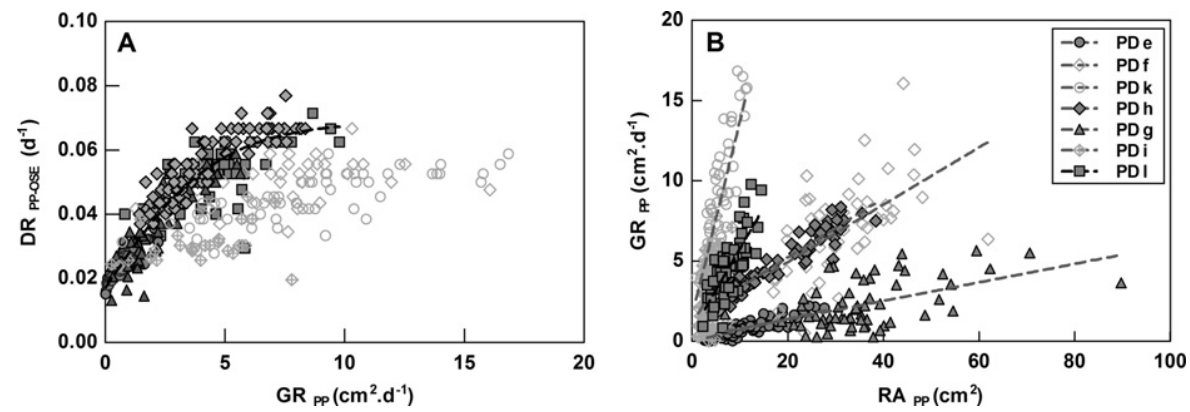

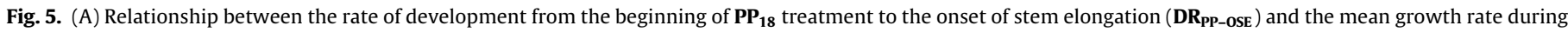

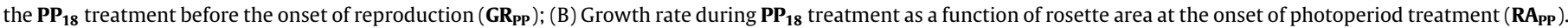

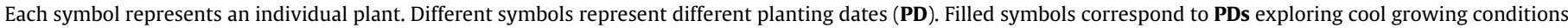

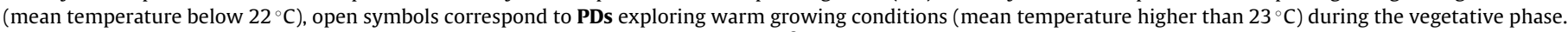

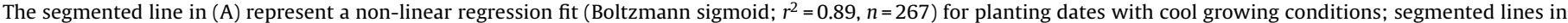
(B) represent linear regression fits for different PDs.

(PP 18 were enough to achieve high percentages of annual plants without vernalization. As Vn+ treatment had an effect in flowering promotion and increased \%An in PDs a and $\mathbf{b}$, vernalization would be a facultative rather than an obligate requirement for flowering in this species.

As regards to photoperiod effects, our results clearly indicate that this species is an obligate long-day plant, in agreement with previous references (Chouard, 1960; Vince-Prue, 1975; Liu et al., 2003) and with our first hypothesis. This response explains why in summer PDs $(\mathbf{f}, \mathbf{k}, \mathbf{1})$ none of the plants exploring decreasing photoperiods $\left(\mathbf{P P}_{\mathbf{N}}\right)$ flowered in the first growing season while most of photoperiod-extended plants (PP18) did so (Fig. 3). In early PDs (autumn-winter, $\mathbf{d}, \mathbf{m}, \mathbf{h}$ ) photoperiod extension had a quantitative effect on time to flowering beginning. Thus, both $\mathbf{P P}_{\mathbf{1 8}}$ and $\mathbf{P P}_{\mathbf{N}}$ achieved $100 \%$ of annual plants, while $\mathbf{P P}_{\mathbf{1 8}}$ flowered earlier.

Although an obligate photoperiod response could explain the qualitative effect of daylength extension in summer PDs and the quantitative effect in autumn-winter ones, it does not explain the high proportion of biennial plants in spring PDs c, $\mathbf{i}$ and $\mathbf{j}$ (Fig. 3), in which photoinductive conditions are satisfied for both $\mathbf{P P}_{\mathbf{1 8}}$ and $\mathbf{P P}_{\mathbf{N}}$ treatments. As PD was delayed from August to November, the proportion of annual $\mathbf{P P}_{\mathbf{N}}$ plants decreased abruptly from 100 to $10 \%$, and this tendency could not be reverted by the $\mathbf{P P}_{\mathbf{1 8}}$ treatment. Therefore, other conditions besides long photoperiods should be met to trigger the flowering response. Our findings suggest that a period of high temperatures just before OSE may act as an
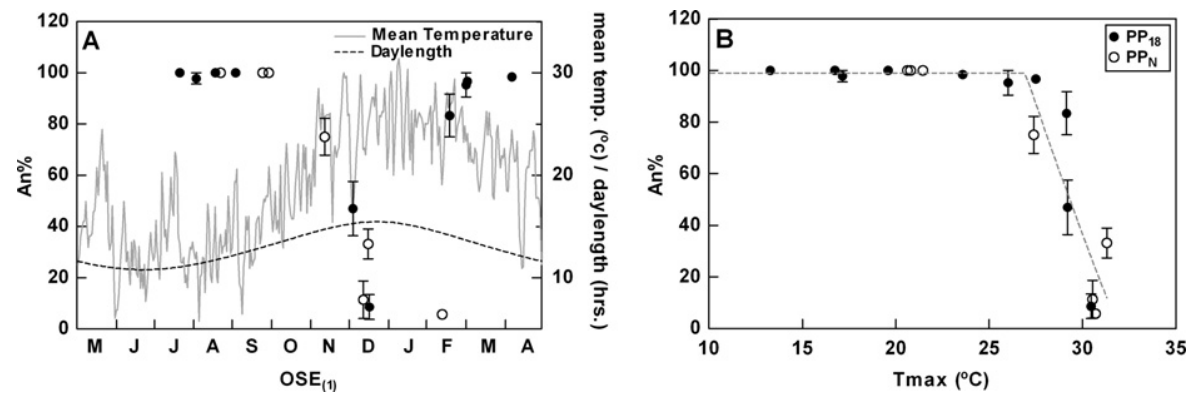

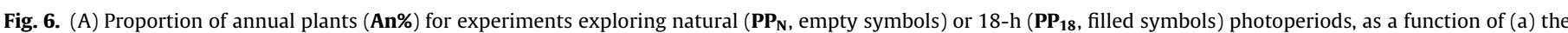

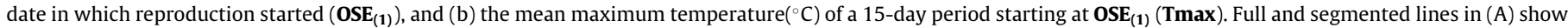

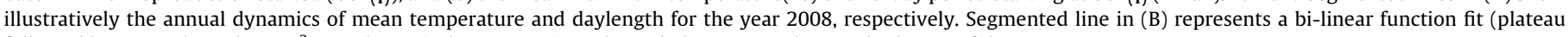
followed by a one phase decay, $r^{2}=0.84$ ). Vertical segments in each symbol represent the standard error of the mean. 
inhibitory factor that would prevent reproduction under otherwise photo-inductive conditions (Fig. 6). For different PDs, we could successfully relate \%An to the mean maximum temperature (Tmax) of an arbitrary $15 \mathrm{~d}$-time window starting at $\mathbf{O S E}_{(\mathbf{1})}$ (when only one or few plants in a treatment reached the reproductive status, while the remaining were still defining whether they will flower - annualsor not - biennials-); the proportion of annual plants decreased abruptly as Tmax increased above a threshold of around $27^{\circ} \mathrm{C}$ (Fig. 6B). Once reproduction is initiated (plants reached the OSE stage), high temperatures would not suppress flowering as arising from the fact that all plants that reached OSE flowered shortly after in our experiments, no matter the environmental conditions. Inhibition of reproduction by high temperatures was also reported for another facultative biennial, Eustoma grandiflorum (Ohkawa et al., 1991; Harbaugh, 1992, 2007).

Concerning our second hypothesis we found that, in agreement with it, the time to reproductive growth initiation (OSE) under inductive photoperiods $\left(\mathbf{P P}_{\mathbf{1 8}}\right)$ depended quantitatively on rosette's growth rate ( $\mathbf{G R}_{\mathbf{P P}}$ ) (Fig. 5A). Under inductive photoperiods and mild temperatures, the higher the $\mathbf{G R}_{\mathbf{P P}}$, the sooner the plant reached the OSE status. This relationship would also explain why in PD c, fertilized plants $(\mathbf{N}+)$ flowered earlier than non-fertilized ones ( $\mathbf{N}-$; Fig. 4B). The quantitative effect of plant growth rate on rate of development toward OSE could also explain the qualitative effect of $\mathbf{N +}$ on $O$. biennis reproductive behavior (i.e. the proportion of plants with annual behavior, \%An; Fig. 4A). Factors that hasten flower transition, like vernalization or photoperiod, but also growth factors such as mineral fertilization $(\mathbf{N}+)$, may exert a positive effect on \%An, by allowing flower induction to occur under adequate conditions for flower transition. As in nature photo-inductive daylengths and inhibiting high temperatures may temporally overlap (Fig. 6A), the success of a crop will depend on its possibility to place the onset of reproduction as early as possible in the spring-summer season, when both photoperiod and temperature are favorable to reproduction. If because of late sowing dates or poor growing conditions (low soil fertility, lack of rainfall, very high plant densities, etc.) flower induction is delayed toward summer, plants will be exposed to inhibiting high temperatures and behave as biennials.

The evidence collected in this work provides an alternative explanation for the influence of rosette size and/or growth factors on 0 . biennis reproductive behavior. Biennial behavior registered in late sown crops (Roy et al., 1993; Król, 2007) or crops grown under restricting growing conditions (Kromer and Gross, 1987; Roy et al., 1993; Small and Catling, 1999; Król and Berbeć, 2004; Król, 2007) would not be the consequence of the non attainment of a critical size for reproduction sensu Werner (1975) and Gross (1981), but the result of delaying flower induction until environmental conditions that inhibit reproduction. Contrary to previous reports on this (Chouard, 1960) and other facultative biennial plant species (Werner, 1975; Baskin and Baskin, 1979; Klinkhamer et al., 1987; Prins et al., 1990), we found no evidence of a critical size for vernalization, as even pre-germinated seeds could respond to the Vn+ treatment by anticipating flowering time (Fig. 2).

In addition, a threshold size for photoperiod response was not evident: rosettes as small as $40 \mathrm{~cm}^{2}$ where observed at OSE state in PD d, while very large rosettes $\left(\mathbf{R A}>600 \mathrm{~cm}^{2}\right)$ of $\mathbf{P P}_{\mathbf{1 8}}$ treatment behaved as biennials in PDs $\mathbf{f}$ and $\mathbf{i}$ (data not shown). Moreover, when $\mathbf{P P}_{\mathbf{1 8}}$ data from different PDs were analyzed together, $\mathbf{R} \mathbf{A}_{\mathbf{P P}}$ was not as a good predictor of rosette development (data not shown) as $\mathbf{G R}_{\mathbf{P P}}$ (Fig. 5A). The fact that $\mathbf{R} \mathbf{A}_{\mathbf{P P}}$ partly determines the subsequent $\mathbf{G R}_{\mathbf{P P}}$ of rosettes, in a different manner for different growing conditions (Fig. 5B), may explain why previous reports on this (Gross, 1981) and presumably other facultative biennials (Kachi and Hirose, 1983, 1985; De Jong et al., 1986; Lacey, 1986; Rees and Rose, 2002) succeeded in predicting flowering behavior from size measurements taken in a given environment, and why the hypothetical threshold size of a species vary across different growing conditions (Wesselingh et al., 1993, 1997; De Jong et al., 1998).

\section{Conclusion}

The control of flowering in 0 . biennis seems to rely on the effect of two main environmental cues: long photoperiod, which is an obligatory requirement for reproduction; and high temperatures blocking flowering under otherwise inductive photoperiodic conditions. As in nature these cues partially overlap, the reproductive behavior of this species strongly depends on when reproduction initiates: as long as plants are exposed to photo-inductive conditions and cool temperatures, they will flower. Since the probability of meeting these conditions is higher early in the spring-summer season, every factor that hastens the rate of development toward reproduction would indirectly promote annual behavior. Besides vernalization, growth rate has a bearing on $O$. biennis rate of development so, in addition to common developmental factors, growth factors can also influence reproductive behavior of this species.

\section{Acknowledgements}

We thank Marisol Berti Diaz for providing the genetic material employed in this work, and Sofía Güell and Luis Pedace for technical assistance in the experiments.

This work was supported by a grant from the University of Buenos Aires (UBACYT G008 and W219).

\section{Appendix A. List of abbreviations}

\begin{tabular}{|c|c|}
\hline H1 & Hypothesis 1 \\
\hline H2 & Hypothesis 2 \\
\hline PD & planting date \\
\hline Vn+ & seed vernalization treatment \\
\hline Vn- & non vernalized treatment \\
\hline $\mathbf{P P}_{\mathbf{N}}$ & natural photoperiod treatment \\
\hline $\mathbf{P P}_{15}$ & 15-h photoperiod treatment \\
\hline $\mathbf{P P}_{18}$ & 18-h photoperiod treatment \\
\hline $\mathbf{N}+$ & fertilized treatment \\
\hline $\mathbf{N}-$ & non fertilized treatment \\
\hline OSE & onset of stem elongation in each plant \\
\hline $\operatorname{OSE}_{(1)}$ & day when the first plant of a treatment reaches OSE \\
\hline FBT & $\begin{array}{l}\text { time from transplant to flowering beginning (first open } \\
\text { flower in each plant) }\end{array}$ \\
\hline$\%$ An & proportion of annual plants in a treatment \\
\hline RA & rosette area $\left(\mathrm{cm}^{2}\right)$ \\
\hline $\mathbf{R} \mathbf{A}_{\mathbf{P P}}$ & $\begin{array}{l}\text { rosette area at the onset of the photoperiod treatment } \\
\left(\mathrm{cm}^{2}\right)\end{array}$ \\
\hline GR & rosette growth rate $\left(\mathrm{cm}^{2} \mathrm{~d}^{-1}\right)$ \\
\hline $\mathbf{G R}_{\mathbf{P P}}$ & $\begin{array}{l}\text { rosette growth rate from the onset of the photoperiod } \\
\text { treatment until } \mathbf{O S E}_{(\mathbf{1})}\left(\mathrm{cm}^{2} \mathrm{~d}^{-1}\right)\end{array}$ \\
\hline DR $_{\text {PP-OSE }}$ & $\begin{array}{l}\text { rate of development from the onset of the photoperiod } \\
\text { treatment to OSE }\left(\mathrm{d}^{-1}\right)\end{array}$ \\
\hline Tmax & $\begin{array}{l}\text { mean maximum temperature }\left({ }^{\circ} \mathrm{C}\right) \text { of a } 15 \mathrm{~d} \text {-time window } \\
\text { starting at } \mathbf{O S E}_{(\mathbf{1})}\end{array}$ \\
\hline
\end{tabular}

\section{References}

Baskin, J.M., Baskin, C.M., 1979. Studies on the autecology and population biology of the weedy monocarpic perennial, Pastinaca sativa. J. Ecol. 67, 601-610.

Berti, M., Wilckens, R., Fischer, S., Hevia, F., Tramón, C., Pertierra, R., 2006. Onagra. In: Oleaginosas Especiales: Alternativas Productivas para el Sur de Chile. Edit. Universidad de Concepción, Chillán, pp. 161-174.

Chouard, P., 1960. Vernalization and its relation to dormancy. Annu. Rev. Plant Physiol. 11, 191-238.

De Jong, T.J., Klinkhamer, P.G.L., Prins, A.H., 1986. Flowering behaviour of the monocarpic perennial Cynoglossum officinale L. New Phytologist 103, 219-229.

De Jong, T.J., Goosen-De Roo, L., Klinkhamer, P.G.L., 1998. Is the threshold size for flowering in Cynoglossum officinale fixed or dependent on environment? New Phytologist 138, 489-496. 
Deng, Y.C., Hua, H.M., Li, J., Lapinskas, P., 2001. Studies on the cultivation and uses of evening primrose (Oenothera spp.) in China. Econ. Bot. 55, 83-92.

Fieldsend, A.F., 2004. Interactive effects of light, temperature and cultivar on photosynthesis in evening primrose (Oenothera spp.) crops. Acta Agron. Hung. 52, 333-342.

Fieldsend, A.F., 2007. The impact of plant breeding on seed oil content and quality in evening primrose crops. In: Proceedings of the Joint International Conference on Long-Term Experiments. Agricultural Research and Natural Resources, Debrecen-Nyírlugos, Hungary, pp. 29-36.

Fieldsend, A.F., Morison, J.I.L., 2000. Contrasting growth and dry matter partitioning in winter and spring evening primrose crops (Oenothera spp.). Field Crop. Res. $68,9-20$.

Ghasemnezhad, A., 2007. Investigations on the effects of harvest methods and storage conditions on yield, quality and germination of evening primrose (Oenothera biennis L.) seeds. Dissertation Submitted for the degree of Doctor of Agricultural Science (Dr. agr.) to the Faculty of Agricultural Sciences, Nutritional and Environmental Management Justus Liebig University Giessen, Germany.

Ghasemnezhad, A., Honermeier, B., 2008. Yield, oil constituents, and protein content of evening primrose (Oenothera biennis L.) seeds depending on harvest time, harvest method and nitrogen application. Ind. Crop. Prod. 28, 17-23.

Grignac, P., 1988. La culture de l'onagre. Oleagineux 43, 119-122.

Gross, K.L., 1981. Prediction of fate from rosette size in four biennial plant species: Verbascum thapsus, Oenothera biennis, Daucus carota and Tragopogon dubius. Oecologia 20, 197-201.

Harbaugh, B.K., 1992. Rosetting of lisianthus cultivars exposed to high temperatures. HortScience 27, 885-887.

Harbaugh, B.K., 2007. Lisianthus, Eustoma grandiflorum. In: Anderson, N.O. (Ed.), Flower Breeding and Genetics Issues, Challenges and Opportunities for the 21st Century. Springer, The Netherlands, pp. 645-663 (Chapter 24).

Horrobin, D.F., 1992. Nutritional and medical importance of gamma-linolenic acid. Prog. Lipid Res. 31, 163-194.

Horrobin, D.F., Lapinskas, P., 1993. Opportunities and markets in the pharmaceutical and health food industry. In: Anthony, K.R.M., Meadley, J., Röbbelen, G. (Eds.), New Crops for Temperate Region. Chapman and Hall, London, pp. 80-90 (Chapter 9).

Hudson, B.J.F., 1984. Evening primrose (Oenothera spp.) oil and seed. J. Am. Oil Chem. Soc. 61, 540-543.

Kachi, N., Hirose, T., 1983. Bolting induction in Oenothera erythrosepala Borbas in relation to rosette size, vernalization and photoperiod. Oecologia (Berl.) 60, 6-9.

Kachi, N., Hirose, T., 1985. Population dynamics of Oenothera glazioviana in a sand-dune system with special reference to the adaptative significance of sizedependent reproduction. J. Ecol. 73, 887-902.

Kagaya, M., Tani, T., Kachi, N., 2009. Variation in flowering size and age of a facultative biennial, Aster kantoensis (Compositae), in response to nutrient availability. Am. J. Bot. 96, 1808-1813.

Kapoor, R., Nair, H., 2005. Gamma linolenic acid oils. In: Sahidi, F. (Ed.), Bailey's Industrial Oil and Fat Product. , 6th ed. John Wiley \& Sons, Inc., Hoboken, NJ, pp. 67-119 (Chapter 4).

Klinkhamer, P.G.L., de Jong, T.J., Meelis, E., 1987. Life-history variation and the control of flowering in short-lived monocarps. Oikos 49, 309-314.

Kromer, M., Gross, K.L., 1987. Seed mass, genotype, and density effects on growth and yield of Oenothera biennis L. Oecologia 73, 207-212.

Król, B., 2007. Growth, development and yielding of biennial evening primrose (Oenothera biennis L.) depending on sowing date on two different soils. Herb. Pol. 53, 191-196.

Król, B., Berbeć, S., 2004. Effect of mineral fertilization on development and seed yield of evening primrose (Oenothera biennis L.). Ann. UMCS E 59, 1731-1737.
Lacey, E.P., 1986. The genetic and environmental control of reproductive timing in a short-lived monocarpic species Daucus carota (Umbelliferae). J. Ecol. 74, 73-86.

Lapinskas, P., 1982. Evening Primrose - Origins and Cultivation. In: Presented at Leatherhead Food Research Association, 9th November 1982, Available from: http://www.lapinskas.com (accessed 30.06.12).

Lapinskas, P., 1993. Oil crops for the pharmaceutical industry. In: Shewry, P., Stobart, K. (Eds.), Seed Storage Compounds: Biosynthesis, Interactions and Manipulation. Oxford University Press, pp. 332-342 (Chapter 23).

Lapinskas, P., 1999. The development of gamma-linolenic acid (GLA) as a pharmaceutical product. In: Presented at Speciality Chemicals for the 21st Century (International Seminar), 19-17 September, Valbonne, France, Available from: http://www.lapinskas.com (accessed 30.06.12).

Little, T.M., Hills, F.J., 1975. Statistical Methods in Agricultural Research. University of California Press, Davis.

Liu, Q.X., Wel, M., Zhu, L.Q., Me, G.M., Vang, Y., 2003. Domestication of Oenothera as a new oil plant. International Atomic Energy Agency Technical Documents IAEA TECDOCs 1369, 117-122.

Lotti, G., Izzo, R., Bottazzi, F., Bellani, A., 1984. Influence dell'epoca di semina sul ciclo di sviluppo della planta e sulle caretteristiche dell'olio di Oenothera biennis L. Agrochimica 28, 85-95.

Ohkawa, K., Kano, A., Kanematsu, K., Korenaga, M., 1991. Effects of air temperature and time on rosette formation in seedlings of Eustoma grandiflorum (Raf.) Shinn. Sci. Hortic. $48,171-176$.

Picard, C., 1967. Action du CCC et du B 995 sur la mise à fleur d'une plante bisannuelle, l' Oenothera biennis. Planta 74, 302-312.

Prins, A.H., Vrieling, K., Klinkhamer, P.G.L., de Jong, T.J., 1990. Flowering behavior of Senecio jacobaea: effects of nutrient availability and size-dependent vernalization. Oikos 59, 248-252.

Reekie, E.H., 1997. Tradeoffs between reproduction and growth influence time of reproduction. In: Bazzaz, F.A. (Ed.), Plant Resource Allocation. Academic Press, New York, pp. 191-209 (Chapter 8).

Reekie, E.G., Reekie, J.Y.C., 1991. The effect of reproduction on canopy structure, allocation and growth in Oenothera biennis. J. Ecol. 79, 1061-1071.

Reeleder, R.D., 1994. Factors affecting infection of evening primrose (Oenothera biennis) by Septoria oenotherae. Can. J. Plant Pathol. 16, 13-20.

Rees, M., Rose, K.E., 2002. Evolution of flowering strategies in Oenothera glazioviana: an integral projection model approach. Proc. R. Soc. Lond. B Biol. Sci. 269, 1509-1515.

Roy, R.C., White, P.H., More, A.F., Hendel, J.G., Pocs, R., Court, W.A., 1993. Effect of transplanting date on the fatty acid composition, oil content and yield of evening primrose (Oenothera biennis L.) seed. Can. J. Plant Sci. 74, 129-131.

Russell, G., 1988. Physiological restraints on the economic viability of the evening primrose crop in eastern Scotland. Crop Res. 28, 25-33.

Small, E., Catling, P.M., 1999. Oenothera biennis (evening primrose). In: Canadian Medicinal Crops. NRC Research Press, Ottawa, Ontario, Canada, pp. 96-101.

Vince-Prue, D., 1975. Vernalization. In: Photoperiodism in Plants. Mc Graw Hill, London, pp. 263-291.

Werner, P.A., 1975. Predictions of fate from rosette size in teasel (Dipsacus fullonum L.). Oecologia (Berl.) 20, 197-201.

Wesselingh, R.A., de Jong, T.J., Klinkhamer, P.G.L., Van Dijk, M.J., Schlatmann, E.G.M., 1993. Geographical variation in threshold size for flowering in Cynoglossum officinale. Acta Bot. Neerl. 42, 81-91.

Wesselingh, R.A., Klinkhamer, P.G.L., De Jong, T.J., Boorman, L.A., 1997. Threshold size for flowering in different habitats: effects of size-dependent growth and survival. Ecology 78, 2118-2132. 